Atıf için / For Citation: Z. ÖZKAN, R. UYHAN, "Sawada-Kotera Denkleminin Nümerik Yöntemlerle Çözümü Ve Çözümlerin Karş1laştırılması”, Süleyman Demirel Üniversitesi Fen Edebiyat Fakültesi Fen Dergisi, 14(2), 256-268, 2019.

\title{
Sawada-Kotera Denkleminin Nümerik Yöntemlerle Çözümü ve Çözümlerin Karşılaştırılması
}

\author{
Zekeriya ÖZKAN ${ }^{* 1}$, Ramazan UYHAN ${ }^{* 2}$ \\ ${ }^{1}$ Cumhuriyet Üniversitesi, Gürün MYO, Bilgisayar Programcllı̆̆ Bölümü, 58800, Gürün/Sivas \\ ${ }^{2}$ Süleyman Demirel Üniversitesi, Fen-Edebiyat Fakültesi, Matematik Bölümü, 32260, Isparta \\ *yazışlan yazar e-posta: zekeriyaozkan@cumhuriyet.edu.tr
}

(Alınış / Received: 20.05.2019, Kabul / Accepted: 02.09.2019, Yayımlanma / Published: 30.11.2019)

Özet: Hesaplama biliminde bilgisayarın etkili ve verimli kullanılması ile beraber kısmi türevli diferansiyel denklemleri çözebilmek için kaynaklarda çok çeşitli metotlar sunulmuştur. Bu metotların bazıları analitik metot çözümü bulurken bazıları algoritma tabanlı yaklaşık çözümü bulan metotlardır. $\mathrm{Bu}$ çalışmada, Sawada-Kotera denklemi çizgiler metodu ve radyal baz fonksiyonları yardımı ile ağsız çizgiler metodu kullanılarak çözülmüştür. Elde edilen sonuçlar üzerinden de bu iki metot karşılaştırılmıştır.

Anahtar kelimeler: Çizgiler Metodu, Ağsız Yöntemler, Radyal Baz Fonksiyonları

\section{Solution of Sawada-Kotera Equation with Numerical Methods and Comparison of Solutions}

\begin{abstract}
Effective and fruitful use of computers in computing science, along with part of the literature, many techniques to obtain the solution of differantial equations is presented. Some of these methods, while achieving analytical technique and some of them algorithm based solution techniques that approximate the solution. In this study, Sawada-Kotera equation is solved using the method of lines and meshless method of lines using radial basis functions. These two methods are compared on the obtained results.
\end{abstract}

Key words: Method of Lines, Meshless Method, Radial Basis Functions

\section{Giriș}

Kısmi diferansiyel denklemler, genelde tabiatın temel kurallarının formülleştirilmesinde ve matematiğin uygulamalı dalı, fiziğin matematiksel dalı ve mühendislik bilimi çözgülerinin matematiksel çözümlemesinde karşımıza gelmektedir. Çoğu zaman bu denklemlerin analitik metotlarla çözümü zor hatta mümkün olmamaktadır. Bundan dolayı böyle denklemlerin sayısal olarak çözümlerinin bulunması gerekebilir [1]. Kısmi türevli diferansiyel denklemlerin çözümleri için analitik ve sayısal olarak birçok metot tanıtılmıştır. Genellikle bu tür denklemlerin sayısal çözümleri gerekmektedir, bunun sebebi sayısal çözümler bilgisayar ile uyumluluğu daha iyi olup, farklı algoritmalarla istenilen sonuçlara daha kolay ulaşılabilmektedir [2]. Doğrusal olmayan kısmi türevli diferansiyel denklemlerin çözümü için sayısal metotların çalışılması son yıllarda hem teori hem de pratik açısından sıklıkla yapılmıştır. Bilgisayar teknolojisindeki hızlı değişmeyle birlikte sayısal metotlardaki ilerlemeler, mühendislik ve başka bilimsel alanlardaki uygulamalarda karşımıza çıkan ve önceleri çözümünde zorlanılan kısmi 
türevli diferansiyel denklemlerin büyük bir kısmının şimdilerde çözülebilecek hale gelmesi demektir [3].

\section{Nümerik Yöntemler}

\subsection{Nümerik Yöntemlerin Genel Özellikleri}

Değişik kısmi türevli diferansiyel denklemlerin çözümünü bulmak için sonlu farklar metodu, sonlu elemanlar metodu, sonlu hacim metodu ve sinır eleman metodu gibi sayısal metotlar kullanılmıştır. Bu metotlar alanı örgü (ağ), 1zgara ya da aralarında sabit iletişim sağlayan noktaların cümlesine ayrıştırır. Örgü yapısında kullanılan birimlerin isimleri önemsizdir. Bu yapıların çözüm aşamasına geçilmeden tanımlanıyor olması önem arz etmektedir. Bu sayede ögelerin (elemanların) veya 1zgaraların kesişme noktaları olan dügümmler arasında ilişki kurularak uygulanacak olan nümerik metodun formülleştirilmesi gerçekleştirilmektedir. Sonlu farklar metodu, genelde standart (kartezyen) koordinatlarda bölgenin muntazam dikdörtgenlere ayrıklaştırılmasıyla bulunan noktalar üzerinde Taylor seri açılımı kullanılarak fark denklemlerinin ifade edilmesini temel alır. Uygulaması oldukça kolay olmasına rağmen özellikle muntazam olmayan bölgelerin ayrıklaştırılması, bölgenin ve problemin fiziksel şartlarının ifade edilmesi açısından sonlu elemanlar metodu kadar etkili değildir. Sonlu elemanlar metodu ve sonlu hacim metodu kompleks geometriyle mücadelede daha esnek olup üç boyutlu problemlerde uygun ağın elde edilmesi, ilgili verilerin yapısı ve bilgisayar programlarının yazılması zorlayıcıdır [4]. Günümüzde mevcut geliştirilebilmiş hali ile sonlu elemanlar metodu, sonlu farklar metodu, sonlu hacim metodu gibi ăg tabanlı metotlar yardımıyla durgun, hareketli, doğrusal ve doğrusal olmayan pek çok problemin çözümü bulunabilmektedir. $\mathrm{Bu}$ problemlerin çözümünde ulaşılmak edilmek istenen çözümün ekonomikliği ve doğruluğunu önemli ölçüde etkileyen dört kıstas aşağıda sıralı şekilde verilmiştir [5]:

1) Çözümlemelerde genellikle zamanın çoğu uygun bir örgü yapısının oluşturulmasına harcanmaktadır. Örgü yapısı çözümleme zamanını ve duyarlılığını önemli ölçüde etkilemektedir. Günümüzde nümerik metotlarla ilgili araştırma noktalarından bir tanesi bu sürecin olabildiğince kısaltılması ve çözümleme duyarlılığının arttırılmasıdır. Bu da insan emeğinin azalması ve bilgisayar kullanımının çoğalması anlamına gelmektedir.

2) Büyük şekil değişimleri ile karşılaşıldığında elemanların çarpılmasından dolayı hesaplanan değerlerin doğruluğu önemli ölçüde düşmektedir.

3) Herhangi bir geometri ya da kompleks bir geometri için çatlak büyümesi probleminin modelleme çalışması ve faz transformasyonun uygulanmasında oldukça zorlanilmaktadir.

4) Sonlu elemanlar metodu sürekli ortam mekaniğini kullandığından, malzeme kırılmasından doğan süreksizliklerde ögeler arasındaki bağların kopması sebebi ile sıkıntılar ortaya çıkabilmektedir.

Dört tanesi belirtilen hataların ve yetersizliklerin asgari düzeye düşürülmesi için çözüm aşamasında ortaya çıkabilen süreksizlik bölgelerinde birbirleriyle ilişkisini kaybeden ögelerin ilişki kurmasını sağlamak amacıyla örgü yapısının yeniden düzenlenmesi gerekmektedir. Ayrıca çözüm aşamasında bağımlı değişkende dönüşüm yapma ihtiyacı gerekmektedir. Bu durum işlem duyarlılığında olumsuz etkilere sebep olur. Bu yüzden çözüm aşamasında daha esnek ve süreksizliğin söz konusu olduğu problemlerde yeni bir örgü yapısının oluşturulmasını gerektirmeyen metotların geliştirilmesi ihtiyacı hasıl olmuştur. Bu sebeple önerilmiş olan ağsız metotlarda bu ihtiyaçların çoğu karşılanabilir 
durumdadır. Örgüsüz metotlarda geometrinin modellenmesi rastgele dağılmış dügümlerle gerçekleştiriliyor olduğundan bu düğümler arasında herhangi bir bağlantının kurulmasına ve dolayısıyla çözüm aşamasında yeni bir örgü yapısının oluşturulması gerekmez [6,22].

\section{2 Çizgiler Metodu}

Kısmi türevli diferansiyel denklemleri çözmede sıkça kullanılan çizgiler metodu (MOL) başka bir yöntemdir. Bu metot, kısmi türevli diferansiyel denklemlerin önemli bölümünün (eliptik, parabolik ve hiperbolik, doğrusal ve doğrusal olmayan, bir, iki ve üç boyutlu gibi) neredeyse tamamına uygulanabilir. Metot ilk önce Alman matematik insanı Erich Rothe tarafından 1930'da parabolik tipteki denklemlerde uygulanmıştır [7,21]. Sonraları fizik bilimindeki sınır değer problemlerini çözmede kullanmak için matematikçiler tarafından geliştirilmiştir $[8,23]$. Doğruluk ve bilgisayar maliyeti açısından, sonlu farklar metodundan daha etkili olan çizgiler tekniği, sonlu farklar tekniğinin daha özel halidir. Bu yöntemde bağımsız değișken $x$ pozisyon (konum) değişkenine göre ayrıklaştırıldığında $t$ zaman değişkeni; $t$ zaman değişkenine göre ayrıklaştırılma yapıldığında ise $x$ pozisyon değişkeni tek olarak bırakılır. Örnek olarak; Meyer yaptığ 1 çalışmalarda genellikle zamanı ayrıklaştırılarak problemi sınır değer problemine indirgemiştir $[9,24]$. Bu çalışmada, $x$ ayrıklaştırıldıktan sonra problem başlangıç değer problemine indirgendi. Ayrıca bilgisayar programlamları yazmada ortaya çıkan zorluk, klasik adi türevli diferansiyel denklem çözme programı yardımıyla düşürülebilir.

\subsection{A ̈̆sız Yöntemler}

A $\breve{g}$ tabanlı metotlarda ortaya çıkan zorluklar, araştırmacıları geleneksel 1zgara tabanlı sayısal metotlara alternatif metotlar aramaya itti. Böylece ağsız metotların yeni dalı ortaya çıktı ve ilk ağsız metot Yumuşatılmış Parçacık Hidrodinamiği 1977'de Gingold ve Monoghan tarafından uzay fiziği problemlerinin benzetimi için tanıtıldı $[10,25]$. Kısmi türevli diferansiyel denklemlerin sayısal çözümünde örgüsüz metotların (MM) özellikle geride kalan 20 yılda cazibesi arttı ve önemli bir gelişim gösterdi. Ağsız metotların (MM) en önemli özelliği ağ ihtiyacı olmaksızın dağılmış düğüm ya da parça kullanarak mümkün olabilen sınır koşulların bütün türleri ile integral denklemleri ya da kısmi türevli diferansiyel denklemler için stabil sayısal çözüm sağlamasıdır. A ğsız metotlarda çözüm bölgesini modellemek ve çözüm aşamasına geçilebilmek için modelleme sırasında düğümler kullanılırken düğümler arasında sonlu elemanlar metodu ile karşılaştırıldığında herhangi bir bağın oluşturulmasına gereksinim kalmamaktadır. $\mathrm{Bu}$ özellik ağsız metotlar için ortaktır. Metotların ağsız olarak adlandırılmasının nedeni de budur. Şimdiye kadar geliştirilen ağsız metotların büyük bir kısmı, çok boyutlu kompleks alan içeren kısmi türevli diferansiyel denklemlerin sayısal çözümü için radyal baz fonksiyonları yardımıyla kollokasyon ağsız metoduna dayanır. Bu çalışmada çizgiler metoduna ve radyal baz fonksiyonları kullanılarak ağsız çizgiler metoduna kısaca değinilerek bazı özel denklemler kullanılarak bu iki yöntem arasında kıyaslamalar yapıldı. Bu kıyaslamalar çerçevesinde problemlerin çözümüne dair yorumlarda bulunuldu.

\subsection{Radyal Baz, Fonksiyonları (RBF)}

Radyal baz fonksiyonları (RBF), sayısal çözümlemede ve istatistikte geniş kullanım alanına sahiptir ve halihazırda matematikçiler için faal bir çalışma alanıdır. Radyal baz 
fonksiyonları değerleri orijine olan uzaklığına dayanan çoğunlukla çok değişkenli fonksiyonlardır. Öyle ki; $\phi(x)=\phi(r) \in \mathbb{R}, x \in \mathbb{R}^{n}$ ve $r \in \mathbb{R}$ dir. Alternatif şekilde $\left\{\boldsymbol{x}_{\boldsymbol{j}}\right\}$ cümlesinde verilen noktaların mesafesine dayanır ve $\phi\left(x-x_{j}\right)=\phi\left(r_{j}\right) \in \mathbb{R}$ dir. $\phi(x)=\phi\left(\|x\|_{2}\right)$ koşulunu sağlayan herhangi bir $\phi$ fonksiyonu radyal fonksiyondur. $r_{j}=\left\|x-x_{j}\right\|_{2}$ normu genellikle Öklid normudur [11,26]. Burada bahsedilen radyal baz fonksiyonların hepsinin tanımında $c$ parametresi bulunur. $\mathrm{Bu}$ c parametresi şekil değişkeni olarak isimlendirilir. $\mathrm{Bu}$ parametrenin radyal baz fonksiyonlarının sayısal metotlara uygulanmada kullanıldığında çözümde oldukça önemli bir etkisi vardır. Bundan dolayı $\boldsymbol{c}$ şekil değişkeninin en uygun değerinin kullanılması oldukça önemlidir. $\mathrm{Bu}$ şekil değişkeninin belirlenmesi hala çalışılan ve hala çözülemeyen bir problemdir [12,27]. Radyal baz fonksiyonları, çok değişkenli fonksiyonlara tek değişkenli fonksiyonların doğrusal bileşeni ile yaklaşmada kullanılan için bir araçtır. $\mathrm{Bu}$ tip yaklaşımlarda esas fayda şudur; hiçbir şekilde örgü gerektirmez ve yüksek boyutlular için keyfi geometri ile çalışır. Çok kullanılan radyal baz fonksiyonları aşağıdaki çizelgede sunulmuştur.

Çizelge 1. Çok kullanılan radyal baz fonksiyonları

\begin{tabular}{cc}
\hline Radyal Baz Fonksiyonlar & $\boldsymbol{\phi}(\boldsymbol{r})$ \\
\hline Çoklu kuadrik (MQ) & $\left(r^{2}+c^{2}\right)^{1 / 2}$ \\
Ters çoklu kuadrik (IMQ) & $\left(r^{2}+c^{2}\right)^{-1 / 2}$ \\
Gauss merkezcil (GA) & $e^{-c^{2} r^{2}}$ \\
\hline
\end{tabular}

\subsection{Yüksek Mertebeden Adi Türevli Diferansiyel Denklemini Birinci Mertebeden Adi Türevli Diferansiyel Denklem Sistemine İndirgeme}

$n$. mertebeden adi türevli diferansiyel denklemi $n$ adet birinci mertebeden adi türevli diferansiyel denklemden meydana gelen bir sistem haline getirmek mümkündür.

$$
y^{(n)}=f\left(y, y^{\prime}, y^{\prime \prime}, \ldots, y^{(n-1)}\right)
$$

şeklinde $n$. mertebeden adi türevli diferansiyel denklemi verilsin. (1) denklemini adi türevli diferansiyel denklem sistemi haline getirmek için

$$
\left\{\begin{array}{c}
y_{1}=y \\
y_{2}=y_{1}^{\prime}=y^{\prime} \\
y_{3}=y_{2}^{\prime}=y^{\prime \prime} \\
\cdot \\
\cdot \\
\cdot \\
y_{n}=y_{n-1}^{\prime}=y^{(n-1)}
\end{array}\right.
$$

olarak $n$ tane değişken gerekir. Bunu yaparken en yüksek mertebeden türev dişında, yeni değişken olarak bilinmeyen fonksiyonlar ve türevleri tanımlanır. (1) denkleminde bu yeni değişkenler yerine yazıldığında

$$
y^{(n)}=f\left(y_{1}, y_{2}, y_{3}, \ldots, y_{n}\right)
$$

şeklinde yeni tanımlanan $n$ adet parametreye bağlı birinci mertebeden bir adi türevli diferansiyel denklem sistemine ulaş1lır. Bu denklem ile $y_{1}, y_{2}, \ldots, y_{n-1}$ 'den oluşan grup 


$$
\left\{\begin{array}{c}
y_{1}^{\prime}=y_{2} \\
y_{2}^{\prime}=y_{3} \\
y_{3}^{\prime}=y_{4} \\
\cdot \\
\cdot \\
\cdot \\
y_{n}^{\prime}=f\left(y_{1}, y_{2}, y_{3}, \ldots, y_{n}\right)
\end{array}\right.
$$

şeklinde birinci mertebeden adi türevli diferansiyel denklem sistemini meydana getirir.

\section{Kullanılan Yöntemler}

\section{1. Çizgiler Yöntemi (MOL)}

Çizgiler yöntemi, bağımsız değişken $x$ konum değişkeni veya $t$ zaman değişkenine bağlı kısmi türevli diferansiyel denklemlerin yerine uygun sonlu fark denklemlerinin yazılması sonucu oluşan adi türevli diferansiyel denklem sisteminin çözülmesiyle sonuca gidilen nümerik çözüm tekniğidir. Bu çalışmada, evolution denklemleri incelenecektir. Evolution denklemlerini temsil etmesi bakımından aşağıdaki (5) denklemi dikkate alınarak çizgiler metodu (MOL) açıklanacaktır [13]:

$$
\frac{\partial u}{\partial t}=K \frac{\partial^{2} u}{\partial x^{2}}
$$

Burada $u, x$ ve $t^{\prime}$ ye bağlı bağımlı değișken, $t$ zamanı temsil eden bağımsız değișken, $x$ pozisyonu temsil eden bağımsız değişken ve $K$ parametresi sabit sayıdır. $\frac{\partial u}{\partial t}$, $u$ 'nun $t$ 'ye göre kısmi türevini göstermektedir. (5) denklemi $t$ değişkenine göre birinci mertebedendir, çünkü $t$ değişkenine göre en yüksek mertebeden kısmi türev birinci mertebedendir. Benzer şekilde, (5) denklemi $x$ değişkenine göre ikinci mertebedendir, çünkü $x$ değişkenine göre en yüksek mertebeden kısmi türev ikinci mertebedendir. (5) denkleminin çözümüne geçmeden önce kısmi türevli diferansiyel denklem probleminin ifadesini tamamlamak için bazı ilave koşulların tanımlanması gerekir. İlave yardımcı koşulların sayısı her bir bağımsız değişkenin türev mertebesine göre belirlenir. (5) denklemi $t$ değişkenine göre birinci mertebeden olduğu için bir tane koşul, $x$ değişkenine göre ikinci mertebeden olduğu için iki tane koşul gereklidir. $t$, başlangıç değer değişkeni olarak isimlendirilir ve bir tane başlangıç koşulu gereklidir. $x$ ise sınır değer değişkeni olarak isimlendirilir ve iki tane sınır koşul gereklidir. Başlangıç değer koşulu

$$
u\left(x, t=t_{b}\right)=u_{0}(x), \quad t_{b} \leq t \leq t_{s}
$$

şeklinde ve sınır değer koşulu

$$
\left\{\begin{array}{l}
u\left(x=x_{b}, t\right)=u_{b}(t) \\
u\left(x=x_{s}, t\right)=u_{s}(t)
\end{array}, x_{b} \leq x \leq x_{s}\right.
$$

şeklinde tanımlansın. (5), (6) ve (7) denklemleri birlikte kısmi türevli diferansiyel denklem problemini teşkil ederler. Bu problemin çizgiler metoduyla çözümü aşağıdaki şekilde açıklanır: 
$x_{b} \leq x \leq x_{s}$ aralı̆̆ında $x_{b}=x_{1}<x_{2}<\ldots<x_{N-1}<x_{N}=x_{s}$ olacak şekilde $N$ tane düğüm olsun. $x_{1}$ ve $x_{N}$ sınır düğümler, $x_{2}, \ldots, x_{N-1}$ iç düğümlerdir. Çizgiler metodunun temel düşüncesi, kısmi türevli diferansiyel denklemlerdeki pozisyon türevlerine sonlu fark eşitlikleri ile yaklaşabilmektir. Bunu yaptığımızda pozisyon türevleri artık pozisyon bağımsız değişkeni ile ifade edilemez. Böylece sadece zaman bağımsız değişkeni kalır. Bir başka deyişle, asıl kısmi türevli diferansiyel denkleme adi türevli diferansiyel denklem sistemi yardımıyla yaklaşılır. Burada yaşanabilecek asıl sıkıntı kısmi türevli diferansiyel denklemi adi türevli diferansiyel denklem sistemi ile açıklamaktır. $\mathrm{Bu}$ yapıldıktan sonra kısmi türevli diferansiyel denklemin sayısal çözümünü bulmak için başlangıç değer adi türevli diferansiyel denklem sistemine herhangi bir integrasyon algoritması uygulanabilir. Bu şekilde çizgiler metodunun en belirgin özelliklerinden biri adi türevli diferansiyel denklem sistemi için var olan, iyi tanımlı sayısal metotların kullanılmasıdır. Bu prosedürü yansitırken öncelikle (5) denklemindeki $u_{x x}$ pozisyon türevi yerine cebirsel yaklaşımını girmek gerekir. Bu durumda

$$
u_{x x} \approx \frac{u_{i+1}-2 u_{i}+u_{i-1}}{(\Delta x)^{2}}
$$

sonlu fark eşitliği kullanılacaktır. Burada $i$, ıgara üzerinde $x$ 'in pozisyonunu anlatan indeks, $\Delta x$ ise 1zgara üzerinde $x$ ekseni boyunca dügümler arası uzaklıktır. O zaman, (5) denkleminin çizgiler metodu yaklaşımı

$$
\frac{d u_{i}}{d t}=D \frac{u_{i+1}-2 u_{i}+u_{i-1}}{(\Delta x)^{2}}, 0 \leq i \leq N
$$

şeklindedir. (9) denklemi adi türevli diferansiyel denklem sistemidir çünkü sadece bir tane bağımsız $t$ değişkenini içerir. (5) kısmi türevli diferansiyel denkleminin, (9) adi türevli diferansiyel denklem sistemine dönüştürülmesi çizgiler metodunun esasıdır. Daha sonra kısmi türevli diferansiyel denklemin çözümünü bulmak için adi türevli diferansiyel denklem sisteminin çözümünü bulmak gerekir. (9) denklem sisteminde $N$ tane başlangıç koşulu gereklidir çünkü $N$ tane adi türevli diferansiyel denklem içerir. Bu koşullar, ayrıklaştırmadan sonra (6) denkleminden

$$
u\left(x_{i}, t=t_{b}\right)=u_{i}(x)=u_{0}\left(x_{i}\right), 0 \leq i \leq N
$$

şeklinde bulunur. Aynı zamanda sınır koşulları

$$
u_{1}(t)=u_{b}(t), u_{N}(t)=u_{s}(t)
$$

şeklinde bulunur. (9), (10) ve (11) denklemleri, verilen kısmi türevli diferansiyel denklemin çizgiler yaklaşımı olarak bulunur. $\mathrm{Bu}$ adi türevli diferansiyel denklem sistemi uygun bir metotla çözülerek elde edilen adi türevli diferansiyel denklem sisteminin çözümü

$$
u_{1}(t), u_{2}(t), \ldots, u_{N}(t)
$$

şeklindedir ki, bu fonksiyonlar $i=1,2, \ldots, N$ 1zgara noktalarında $u(x, t)$ 'ye yaklaşır [14]. Başlangıçta ele alınan kısmi türevli diferansiyel denklem eğer bir başlangıç-değer problemi ise sonuçta oluşan adi türevli diferansiyel denklem sistemi de bir başlangıç 
değer problemidir. Eğer problem bir sınır değer problemi ise sonuçta oluşan adi türevli diferansiyel denklem sistemi de sınır değer problemidir [15].

\subsection{A Ăsız Metotlar}

A ̆gsı metot (MM), tanımlanan alanda ăg kurulmadan sistemin algoritmik denklemlerini kurmaya çalışan bir metod olarak tanımlanabilir. A ğsız metotlar problem bölgesinde tanımlı düğüm noktalarını kullanarak sınır şartlarını uygulayıp problemi çözer. Dağılmış düğümlere alan düğümleri denir ve aralarında ağ oluşturmazlar [16]. Sonlu elemanlar metodunda olduğu gibi uygun olan ara değer bulma (interpolasyon) veya yaklaşık çözümü bulmak için önceden ă̆ tanımlanması gerekmemektedir. Standart koordinatlarda $u(x, t)$ fonksiyonu için ağsız yaklaşım

$$
u^{N}(x, t) \approx u(x, t)=\sum_{I \in S} \varphi_{I}(x) u_{I}(t)
$$

şeklinde tanımlanır. Burada $\varphi_{I}: \Omega \rightarrow \mathbb{R}$ şekil fonksiyonları, $u_{I}{ }^{\prime}$ lar $I$ parçasında $x_{I}$ pozisyonundaki düğüm değerleri, $S$ ise $\varphi_{I}(x) \neq 0$ olmak üzere $I$ parçasındaki dügümlerin cümlesidir. (13) formu sonlu elemanlar yaklaşımına benzemekle birlikte, $u_{I} \neq u\left(x_{I}\right)$ olduğu için (13) denklemindeki şekil fonksiyonları sonlu elemanlar metodunun aksine sadece yaklaşım olup ara değer bulma değildir [17].

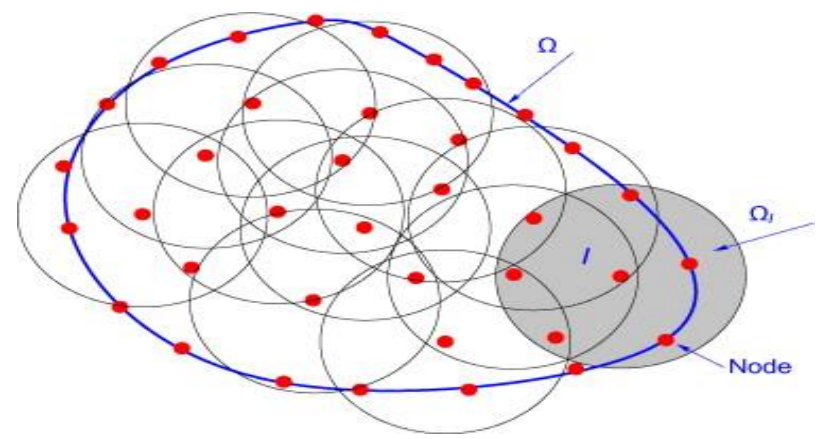

Şekil 1. Ağsız yöntemler kullanılarak alanı ayrıklaştırma

\subsection{Radyal Baz Fonksiyonları Yardımıyla Ăgsız Çizgiler Metodu (MMOL-RBF)}

Radyal baz fonksiyonları yardımıyla ağsız çizgiler metodunu (1+1) boyutlu kısmi türevli diferansiyel denklemler için nasıl uygulanacağından bahsedilmiştir.

\subsubsection{Birinci mertebeden (1+1) boyutlu kısmi türevli diferansiyel denklemler için MMOL-RBF}

Birinci mertebeden $(1+1)$ boyutlu kısmi türevli diferansiyel denklemlere radyal baz fonksiyonları yardımıyla ağsız çizgiler metodunu (MMOL-RBF) uygulamak için $u=u(x, t)$ ve $L$ pozisyon türev operatörü olmak üzere

$$
\frac{\partial u}{\partial t}+L(u)=0, x \in \Omega, t \geq 0
$$

formundaki kısmi türevli diferansiyel denklemleri ele alalım. Şimdi varsayalım ki; $x_{1}, x_{2}, \ldots, x_{N}$ düğümleri $\Omega \subset \mathbb{R}$ problem alanındaki merkezin cümlesinde seçilen düğümler olsun. Zaman bağımlı kısmi türevli diferansiyel denklemler için radyal baz 
fonksiyonları yardımıyla ağsız çizgiler metodunda sunulan fikirler aşağıdadır [18]. $u^{N}(x, t)$ yaklaşık çözümü

$$
u^{N}(x, t)=\sum_{j=1}^{N} \lambda_{j}(t) \Psi\left(\left\|x-x_{j}\right\|\right)
$$

olarak verilebilir. Burada $\Psi$ bazı radyal baz fonksiyonları, $x_{j}{ }^{\prime}$ ler merkezdeki dügüümler ve $\lambda_{j}(t), j=1,2, \ldots, N$ belirlenecek olan bilinmeyen katsayılardır. Benzeri olarakta pozisyon türev operatörü için yaklaş1k çözüm

$$
L\left(u^{N}(x, t)\right)=\sum_{j=1}^{N} \lambda_{j}(t) L\left(\Psi\left(\left\|x-x_{j}\right\|\right)\right)
$$

olarak yazılabilir. (15) ve (16) denklemlerindeki yaklaşımlar matris formunda

$$
\left\{\begin{array}{c}
u^{N}=A \lambda \\
L\left(u^{N}\right)=B \lambda
\end{array}\right.
$$

olarak yazılabilir. Burada

$$
\begin{gathered}
u^{N}=\left[u_{1}(t), u_{2}(t), \ldots, u_{N}(t)\right]^{T} \\
L\left(u^{N}\right)=\left[L\left(u_{1}(t)\right), L\left(u_{2}(t)\right), \ldots, L\left(u_{N}(t)\right)\right]^{T} \\
\lambda=\left[\lambda_{1}(t), \lambda_{2}(t), \ldots, \lambda_{N}(t)\right]^{T}
\end{gathered}
$$

şeklinde sütun matrisleri, A ise $A_{i, j}=\Psi\left(\left\|x_{i}-x_{j}\right\|\right), i, j=1, \ldots, N$ şeklinde ögeleri olan matris ve $\mathrm{B}$ ise $B_{i, j}=L \Psi\left(\left\|x_{i}-x_{j}\right\|\right)_{x=x_{j}}, i, j=1, \ldots, N$ şeklinde ögeleri olan simetrik olmayan matristir. (17) denklemleri kullanılarak

$$
L\left(u^{N}\right)=D u^{N}
$$

olarak yazılabilir. Burada $D=B A^{-1}$ 'dir. Radyal baz fonksiyonları yardımıyla konum değişkenine göre ayrıklaştırıldıktan sonra, (14) kısmi türevli diferansiyel denklemi

$$
\frac{d u_{i}}{d t}=D u^{N}, \quad i=1, \ldots, N
$$

ile verilen adi türevli diferansiyel denklem sistemi bulunur. (22) denklem sistemi uygun bir adi türevli diferansiyel denklem çözme metoduyla çözülür.

\section{Uygulamalar}

Bu bölümde Sawada-Kotera denkleminin çizgiler yöntemi ve çoklu kuadrik (MQ), ters çoklu kuadrik (IMQ) ve gauss merkezcil (GA) radyal baz fonksiyonları yardımıyla 
örgüsüz çizgiler metodu ile çözümleri elde edilip, nümerik değerleri çizelgeler halinde verilmiştir. Ayrıca metodun performansını değerlendirmek için aşağıdaki hata normları kullanılmıştır:

$$
\begin{gathered}
L_{2}=\left\|u^{N}-u\right\|_{L_{2}}=\sqrt{h \sum_{i=1}^{N}\left(u_{i}^{N}-u_{i}\right)^{2}} \\
L_{\infty}=\left\|u^{N}-u\right\|_{L_{\infty}}=\max _{1 \leq i \leq N}\left|u_{i}^{N}-u_{i}\right|
\end{gathered}
$$

Burada $\boldsymbol{u}$ analitik çözümü, $u^{N}$ nümerik çözümü temsil eder. Konumda ve zamanda noktasal yakınsaklık oranlarını hesaplamak için aşağıdaki formüller kullanılmıştır:

$$
\begin{aligned}
& \frac{\log \left(\left\|u_{\text {analitik }}-u_{h_{i}}\right\| /\left\|u_{\text {analitik }}-u_{h_{i+1}}\right\|\right)}{\log \left(h_{i} / h_{i+1}\right)} \\
& \frac{\log \left(\left\|u_{\text {analitik }}-u_{t_{i}}\right\| /\left\|u_{\text {analitik }}-u_{t_{i+1}}\right\|\right)}{\log \left(t_{i} / t_{i+1}\right)}
\end{aligned}
$$

Burada $u_{\text {analitik }}$ analitik çözümü $u_{h_{i}}$ ve $u_{t_{i}}$ ise sırasıyla $h_{i}$ ve $t_{i}$ adımları ile nümerik çözümü temsil eder.

\subsection{Sawada-Kotera Denklemi}

$$
u_{t}+\alpha u^{2} u_{x}+\beta u_{x} u_{x x}+\gamma u u_{x x x}+u_{x x x x x}=0
$$

denklemi ile Sawada-Kotera denklemini ele alalım. Burada $\alpha, \beta, \gamma$ sifirdan farklı keyfi sabitler ve $u=(x, t)$ yeterince türevlenebilen fonksiyondur. $\alpha=45, \beta=\gamma=15$ ve $-15 \leq x \leq 15,0 \leq t \leq 1, N=11$ alarak denklemi klasik çizgiler yöntemini ve radyal baz fonksiyonları yardımıyla örgüsüz çizgiler metodunun kullanarak çözelim. Denklemin analitik çözümü

$$
u(x, t)=2 k^{2} \operatorname{sech}^{2}\left(k\left(x-16 k^{4} t-x_{0}\right)\right)
$$

şeklindedir [19]. Burada $k$ ve $x_{0}$ keyfi parametrelerdir. Bu çalışmada $k=0.01, x_{0}=0$ olarak alınmıştır. Başlagınç şartı ise denklem (24)'den elde edilir.

\subsection{1. Çizgiler Yöntemi ile Çözüm}

Burada (23) denkleminin $x$ değişkenini verilen aralıkta $N$ parçaya ayıralım.

$$
x_{i}=i . h(i=1,2, \ldots, N)
$$

olup burada $h=\frac{15-(-15)}{N}$ ile hesaplanır. (23) denkleminde $u_{x}, u_{x x}, u_{x x x}$ ve $u_{x x x x x}$ ifadelerinin yerine sonlu fark yaklaşımlarını yazarsak 


$$
\frac{d u_{i}}{d t}=f\left(u_{i}\right), \quad i=1,2, \ldots, N
$$

şeklinde $t$ 'ye bağlı bir adi türevli diferansiyel denklem sistemi oluşur. Oluşan adi türevli diferansiyel denklem sistemi MATLAB paket program aracilığıyla Runge-Kutta yöntemi kullanılarak çözülmüştür [14]. Elde edilen sonuçlar analitik çözümle $L_{2}$ ve $L_{\infty}$ hata normlarına göre kıyaslanarak Çizelge 2, Çizelge 3 ve Çizelge 4 'te verilmiştir.

\subsubsection{Radyal Baz, Fonksiyonları Yardımıyla Örgüsüz Çizgiler Yöntemi ile Çözüm}

$\mathrm{Bu}$ denklemin radyal baz fonksiyonları yardımıyla örgüsüz çizgiler metodu ile çözümü şu şekildedir: öncelikle $[-15,15]$ problem alanında $N$ değerine göre düzgün aralıklı (uniform) düğüm dağılımı yapılır. $\mathrm{Bu}$ ayrıklaştırma sürecinde yaklaşık çözüm $u^{N}(x, t)$ 'den, (17)'deki denklemlerden $u^{N}=A \lambda$ yazılabilir. (23) denklemi $x$ değişkenine göre bir, iki, üç ve beşinci mertebeden türevler içerdiği için (21) denkleminden

$$
\left\{\begin{aligned}
u_{x}^{N} & =D_{x} u^{N} \\
u_{x x}^{N} & =D_{x x} u^{N} \\
u_{x x x}^{N} & =D_{x x x} u^{N} \\
u_{x x x x x}^{N} & =D_{x x x x x} u^{N}
\end{aligned}\right.
$$

elde edilir. (17) ve (26) denklemleri (23) denkleminde yerine yazılırsa

$$
\frac{d u_{i}^{N}}{d t}+a\left(u_{i}^{N}\right)^{2}\left(D_{x} u^{N}\right)+\beta\left(D_{x} u^{N}\right)\left(D_{x x} u^{N}\right)+\gamma\left(u_{i}^{N}\right)\left(D_{x x x} u^{N}\right)+D_{x x x x x} u^{N}=0
$$

denklem sistemine ulaşılır. Ayrıklaştırma sonrası başlangıç koşulu (24) denkleminden

$$
u_{i}(0)=2 k^{2} \operatorname{sech}^{2}\left(k\left(x_{i}-x_{0}\right)\right), i=1, \ldots, N
$$

olur. Böylece (23) ve (24) denklemleriyle ifade edilen kısmi türevli diferansiyel denklem problemi (27) ve (28) denklemleriyle ifade edilen adi türevli diferansiyel denklem sistemi problemine indirgenmiş olur. Bulunan bu adi türevli diferansiyel denklem sisteminin çözümü, dördüncü dereceden Runge-Kutta yöntemi, ODE45 komutu ile MATLAB paket program aracılığıyla elde edilmiştir [14]. Elde edilen sonuçlar analitik çözümle zamanda noktasal yakınsaklık oranı, $L_{2}$ hata normuna ve $L_{\infty}$ hata normlarına göre kıyaslanarak sırasıyla Çizelge 2, Çizelge 3 ve Çizelge 4 'te verilmiştir. 
Çizelge 2. Sawada-Kotera denklemi için $L_{2}$ hata normu

\begin{tabular}{clllcc}
\hline Yöntem & $\boldsymbol{t}=\mathbf{0 . 0 0 1}$ & $\boldsymbol{t}=\mathbf{0 . 0 0 2}$ & $\boldsymbol{t}=\mathbf{0 . 0 1}$ & $\boldsymbol{t}=\mathbf{0 . 0 5}$ & $\boldsymbol{t}=\mathbf{0 . 1}$ \\
\hline \multirow{2}{*}{ MOL-Klasik } & 3,9581974998 & 1,5831606685 & 3,9495584895 & 6,1919363486 & 1,2421913912 \\
& $3952 \times 10^{-14}$ & $7293 \times 10^{-13}$ & $5172 \times 10^{-12}$ & $5275 \times 10^{-9}$ & $2962 \times 10^{-8}$ \\
\multirow{3}{*}{ MMOL-GA } & 5,3311595664 & 1,0598727531 & 5,0539128688 & 2,0165151478 & 3,1232020864 \\
& $61482 \times 10^{-8}$ & $05454 \times 10^{-7}$ & $56254 \times 10^{-7}$ & $80510 \times 10^{-6}$ & $96560 \times 10^{-6}$ \\
\multirow{3}{*}{ MMOL-MQ } & 2,1303217122 & 4,2660592357 & 2,1551272475 & 1,1392342595 & 2,4699942294 \\
& $12969 \times 10^{-9}$ & $29185 \times 10^{-9}$ & $85653 \times 10^{-8}$ & $43211 \times 10^{-7}$ & $96117 \times 10^{-7}$ \\
\multirow{2}{*}{ MMOL-IMQ } & 2,7244629375 & 5,4305471394 & 2,6433956258 & 1,1617699822 & 2,0000950067 \\
& $27260 \times 10^{-8}$ & $01527 \times 10^{-8}$ & $07828 \times 10^{-7}$ & $72734 \times 10^{-6}$ & $35073 \times 10^{-6}$ \\
\hline
\end{tabular}

Çizelge 2. Sawada-Kotera denklemi için zamanda noktasal yakınsaklık oranı

\begin{tabular}{|c|c|c|c|c|c|}
\hline Yöntem & $d t$ & $L_{2}$ & $L_{2}$ Oran & $\boldsymbol{L}_{\infty}$ & $L_{\infty}$ Oran \\
\hline \multirow{2}{*}{ MOL-Klasik } & \multirow{2}{*}{0.0004} & 3,0902828107 & 1,999918057 & 9,600700554237 & 1,00048009 \\
\hline & & $96819 \times 10^{-14}$ & 526170 & $670 \times 10^{-14}$ & 673645 \\
\hline \multirow{2}{*}{ MMOL-MQ } & \multirow{2}{*}{0.0004} & 1,4385336855 & 1,0960 & 7,195635233 & 1,096 \\
\hline & & $87527 \times 10^{-7}$ & 62 & $256 \times 10^{-}$ & \\
\hline \multirow{2}{*}{ MMOL-IMQ } & \multirow{2}{*}{0.0004} & 1,3881552617 & 0,809719995 & 6,208019057 & $0,809^{7}$ \\
\hline & & $35297 \times 10^{-7}$ & 313 & $272 \times 10^{-}$ & 531 \\
\hline \multirow{2}{*}{ MMOL-GA } & \multirow{2}{*}{0.0004} & 2.3454692649 & 0,672801736 & 1,049581465870 & 0,67280173 \\
\hline & & $38425 \times 10^{-6}$ & 081 & $597 \times 10^{-}$ & 32 \\
\hline \multirow{2}{*}{ MOL-Klasik } & \multirow{2}{*}{0.0002} & 3,0902827460 & 1,999930653 & 9,600700554237 & 1,00004803 \\
\hline & & $95657 \times 10^{-14}$ & 555113 & $670 \times 10^{-1}$ & 2015435 \\
\hline \multirow{2}{*}{ MMOL-MQ } & \multirow{2}{*}{0.0002} & 1,3878532813 & 1,092168404 & 6,942126946767 & 1,09217594 \\
\hline & & $72341 \times 10^{-7}$ & 454157 & $579 \times 10$ & 1817379 \\
\hline \multirow{2}{*}{ MMOL-IMQ } & \multirow{2}{*}{0.0002} & 1,3516365318 & 0,815519726 & 6,044702332075 & 0,81551972 \\
\hline & & $27191 \times 10^{-6}$ & 896214 & $313 \times 10^{-}$ & 6896247 \\
\hline \multirow{2}{*}{ MMOL-GA } & \multirow{2}{*}{0.0002} & 2,2938797537 & 0,682373345 & 1,026495511917 & 0,68237334 \\
\hline & & $34842 \times 10^{-6}$ & 427745 & $511 \times 10^{-}$ & 2623867 \\
\hline \multirow{2}{*}{ MOL-Klasik } & \multirow{2}{*}{0.0001} & 3,0902827460 & 1,999928186 & 9,600700554280 & 1,00004807 \\
\hline & & $95657 \times 10^{-14}$ & 581897 & $002 \times 10^{-}$ & 1386950 \\
\hline \multirow{2}{*}{ MMOL-MQ } & \multirow{2}{*}{0.0001} & 1,3878532804 & 1,092076489 & 6,942126942039 & 1,09208402 \\
\hline & & $27078 \times 10^{-7}$ & 807672 & $017 \times 10^{-}$ & 0401946 \\
\hline \multirow{2}{*}{ MMOL-IMQ } & \multirow{2}{*}{0.0001} & 1,3516365304 & 0,815658134 & 6,044702326064 & 0,81565813 \\
\hline & & $83120 \times 10^{-6}$ & & & 464 \\
\hline \multirow{2}{*}{ MMOL-GA } & \multirow{2}{*}{0.0001} & 2,2938797414 & 0,682601912 & 1,026495506420 & 0,68260190 \\
\hline & & $50826 \times 10^{-6}$ & & $497 \times 10^{-}$ & \\
\hline \multirow{2}{*}{ MOL-Klasik } & \multirow{2}{*}{0.00005} & 2,1460435927 & 1,999990244 & 8,000519802571 & 1,00004015 \\
\hline & & $06593 \times 10^{-14}$ & 197298 & $813 \times 10^{-}$ & \\
\hline \multirow{2}{*}{ MMOL-MQ } & \multirow{2}{*}{0.00005} & 1,3878532805 & 1,092030602 & 6,942126942665 & 1,09203812 \\
\hline & & $52346 \times 10^{-7}$ & & $652 \times 10$ & 9667741 \\
\hline \multirow{2}{*}{ MMOL-IMQ } & \multirow{2}{*}{0.00005} & 1,3516365303 & 0,815727511 & 6,044702325637 & 0,81572751 \\
\hline & & $87683 \times 10^{-6}$ & 264141 & $636 \times 10^{-7}$ & 1264141 \\
\hline & 0 & 2,2938797402 & 0,682717002 & 1,026495505888 & 0,68271699 \\
\hline IV & 000 & $62165 \times 10^{-6}$ & 488768 & $579 \times 10^{-6}$ & 8687448 \\
\hline
\end{tabular}


Çizelge 4. Sawada-Kotera denklemi için $L_{\infty}$ hata normu

\begin{tabular}{cccccc}
\hline Yöntem & $\boldsymbol{t}=\mathbf{0 . 0 0 1}$ & $\boldsymbol{t}=\mathbf{0 . 0 0 2}$ & $\boldsymbol{t}=\mathbf{0 . 0 1}$ & $\boldsymbol{t}=\mathbf{0 . 0 5}$ & $\boldsymbol{t}=\mathbf{0 . 1}$ \\
\hline \multirow{2}{*}{ MOL-Klasik } & 1,2346552134 & 2,4694628324 & 1.2353409818 & 9,7693942243 & 3,8555565963 \\
& $4649 \times 10^{-10}$ & $8934 \times 10^{-10}$ & $9410 \times 10^{-9}$ & $7418 \times 10^{-11}$ & $67256 \times 10^{-10}$ \\
\multirow{2}{*}{ MMOL-GA } & 2,3856574769 & 4,7428581462 & 2,2615914730 & 9,0237674692 & 1,3976115853 \\
& $08867 \times 10^{-8}$ & $30167 \times 10^{-8}$ & $07121 \times 10^{-7}$ & $10763 \times 10^{-7}$ & $38859 \times 10^{-6}$ \\
\multirow{2}{*}{ MMOL-MQ } & 1,0655923663 & 2,1389398242 & 1,0780012879 & 5,6985123045 & 1,2355125744 \\
& $73939 \times 10^{-9}$ & $7743 \times 10^{-9}$ & $22601 \times 10^{-8}$ & $9670 \times 10^{-8}$ & $64254 \times 10^{-7}$ \\
\multirow{2}{*}{ MMOL-IMQ } & 1,2184168660 & 2,4286145117 & 1,1821624621 & 5,1955933091 & 8,9446967930 \\
& $97943 \times 10^{-8}$ & $43768 \times 10^{-8}$ & $46380 \times 10^{-7}$ & $61116 \times 10^{-7}$ & $35045 \times 10^{-7}$ \\
\hline
\end{tabular}

\section{Sonuç ve Yorum}

Çizelgelerden şu sonuç çıkarılmıştır: Klasik çizgiler yöntemi, radyal baz fonksiyonları yardımıyla örgüsüz çizgiler metoduna göre daha iyi sonuçlar vermiştir. Çizelge 3 'ten görülür ki: $N$ sayısının değişimi denklem sonucunda kayda değer bir değişiklik meydana getirmemiştir. Yani küçük $N$ değerleri ile zaman kaybı yaşamadan eş değer doğrulukta sonuçlar bulunabilir ki bu da yöntemi çekici kılan avantajlardan biridir. Bu çalışmada, klasik çizgiler yöntemi ve radyal baz fonksiyonları yardımıyla örgüsüz çizgiler metodu hakkında bilgiler verilerek Sawada-Kotera denklemine nasıl uygulanacağını göstermek için uygulamalar sunulmuştur. Elde edilen sonuçlar $L_{2}$ ve $L_{\infty}$ hata normları ile zamanda noktasal yakınsaklık oranı hesaplanarak kıyaslamalar yapılmıştır. Klasik çizgiler yöntemi ve ağsız çizgiler yöntemi sonucunda oluşan adi türevli diferansiyel denklem sistemi Runge-Kutta yöntemi ile MATLAB paket programları aracılığıyla çözülmüştür. E. Rothe tarafindan 1930'da geliştirilen klasik çizgiler metodu [20] ile radyal baz fonksiyonları yardımıyla örgüsüz çizgiler metodu karşılaştırıldığında yararlılıklarını şöyle sıralayabiliriz:

1) Klasik çizgiler yönteminde türevlere sonlu farklar formülü kullanılarak yaklaşılmıştır. Bu sırada problem çözümü için ağ inşa edilmiştir ki bu çizgiler yönteminin en büyük dezavantajıdır. Çünkü bu süreç oldukça zaman alıcı ve zordur. Buna rağmen radyal baz fonksiyonları yardımıyla örgüsüz çizgiler metodu ile karşılaştırıldığına klasik çizgiler metodu daha hassas sonuçlar vermiştir.

2) Ağsız çizgiler yönteminde ise şekil fonksiyonu olarak çoklu kuadrik fonksiyonu (MQ), ters çoklu kuadrik fonksiyonu (IMQ) ve gauss merkezcil fonksiyonu (GA) kullanılmıştır. Radyal baz fonksiyonları kullanılarak örgüsüz çizgiler metodu ağ tabanı gerektirmeden çözüm üretildiği için daha kolaydır ve bu yöntem başka lineer olmayan problemlere kolaylıkla uygulanabilir. Ancak bu metotta karşımıza çıkan $\boldsymbol{c}$ şekil parametresinin belirlenmesi ve $A$ interpolason matrisinin terslenememesi yöntemin dezavantajidir.

3) Her iki yöntemde de düşük pozisyon düğüm sayısına rağmen oldukça yüksek oranlı doğrulukta sonuçlar elde edilmektedir.

4) Yöntemler pozisyon boyutundan bağımsızdır. Yani $(\mathrm{N}+1)$ boyutlu kısmi türevli diferansiyel denklemlere metot kolaylıkla uygulanabilmektedir.

\section{Kaynakça}

[1] L. Debnath, Nonlinear Partial Differential Equations for Scientists and Engineers (3th ed.). Edinburg: Birkhauser, 2005. 
[2] İ. Çağlar, "Bazı özel kısmi türevli diferansiyel denklemlerin gezen dalga çözümleri,” Yüksek Lisans Tezi, Fen Bilimleri Enstitüsü, Selçuk Üniversitesi, Konya, Türkiye, 2012.

[3] A.R. Mitchell, D.F. Griffiths, The Finite Difference Method in Partial Equations. Chichester: John Wiley \& Sons, 1980.

[4] L. Demkowicz, J.T. Oden, W. Rachowicz and O. Hardy, "Toward A universal h-p adaptive finite element strategy, part 1: constrained approximation and data structure", Comput. Methods Appl. Mech. Eng., 77 (1), 79-112, 1989.

[5] G.R. Liu, Meshfree Methods: Moving Beyond the Finite Element Method. Boca Raton: CRC Press, 2003.

[6] S. Çalışkan, "Eleman bağımsız Galerkin ve yerel Petrov Galerkin ağsız yöntemlerinin bir boyutlu mühendislik problemlerine uygulaması," Yüksek Lisans Tezi, Fen Bilimleri Enstitüsü, Karadeniz Teknik Üniversitesi, Trabzon, Türkiye, 2006.

[7] R. Pregla, Analysis of Electromagnetic Fields and Waves: The Method of Lines. West Sussex: John Wiley \& Sons, 2008.

[8] W.E. Schiesser, The Numerical Method of Lines: Integration of Partial Differential Equations. San Diego: Academic Press, 1991.

[9] G.H. Meyer, The Time-Discrete Method of Lines for Options and Bonds A PDE Approach. Singapore: World Scientific Publishing, 2015.

[10] R.A. Gingold and J.J. Monaghan, "Smoothed particle hidrodinamics: theory and application to nonspherical stars," Mon. Not. R. Astr. Soc., 181, 375-389, 1977.

[11] W. Chen, Z. Fu and C.S. Chen, Recent Advances in Radial Basis Function Collocation Methods. New York: Springer, 2014.

[12] Q. Shen, "A meshless method of lines for the numerical solution of KdV equation using radial basis functions," Eng. Anal. Bound. Elem., 33, 1171-1180, 2009.

[13] W.E. Schiesser and G.W. Griffiths, A Compendium of Partial Differential Equation Models: Method of Lines Analysis with Matlab. Cambridge: Cambridge University Press, 2009.

[14] W.E. Schiesser and G.W. Griffiths, Traveling Wave Analysis of Partial Differantial Equations. San Diego: Academis Press, 2012.

[15] F. Durmuş, "Kısmi türevli diferansiyel denklemlerin nümerik çözümü için method of lines yöntemi," Yüksek Lisans Tezi, Fen Bilimleri Enstitüsü, Selçuk Üniversitesi, Konya, Türkiye, 2015.

[16] G.R. Liu and Y.T Gu, An Introduction to Meshfree Methods and Their Programming. Dordrecht: Springer, 2005.

[17] V.P. Nguyen, T. Rabczuk, S. Bordas and M. Duflot, "Meshless methods: a review and computer implementation aspects,", Math. Comput.Simulat., 79, 763-813, 2008.

[18] N. Bibi, "Meshless method of lines for numerical solutions of nonlinear time dependent partial differential equations," $\mathrm{PhD}$ Thesis, Ghulam Ishaq Khan of Engineering Sciences and Technology, Swabi, Pakistan, 2011.

[19] D. Kaya and S.M. El-Sayed, “On a Generalized fifth order KdV equations,” Phys. Lett. A., 310, 44$51,2003$.

[20] C. Köroğlu, "Üstel matris fonksiyonları yardımıyla amerikan opsiyon probleminin çizgiler yöntemi ile çözümü,” Doktora Tezi, Fen Bilimleri Enstitüsü, Ege Üniversitesi, İzmir, Türkiye, 2002.

[21] F. Tchier, Mustafa İnc, Bülent Kılıç and Ali Akgül, "On soliton structures of generalized resonance equation with time dependent coefficients," Optik, 128, 218-223, 2017.

[22] A. Akgül, Mustafa İnç and Esra Karataş, "Reproducing kernel functions for difference equations," Discrete Contin. Dyn. Syst. Ser., 8(6), 1055-1064, 2015.

[23] A. Akgül, A. Kılıçman, and Mustafa İnç, "Improved (G '/G)-expansion method for the space and time fractional foam drainage and KdV equations," Abstr. Appl. Anal., (Article ID: 414353), 7 pages, 2013.

[24] A. Akgül, Y. Khanb, E. Karataş Akgül, D. Baleanu and M. M. Al Qurashi, "Solutions of nonlinear systems by reproducing kernel method," J. Nonlinear Sci. Appl., 10, 4408-4417, 2017.

[25] A. Akgül, "New reproducing kernel functions," Math. Probl. Eng., (Article ID:158134), 10 pages, 2015.

[26] M. İnç and A. Akgül, "Approximate solutions for MHD squeezing fluid flow by a novel method," Bound. Value Probl., 2014 (Article ID:18), 18 pages, 2014.

[27] M.İnç, B. Kılıç, E. Karataş and A. Akgül, "Solitary wave solutions for the Sawada-Kotera equation," J. Adv. Phys., 6 (2), 288-293, 2017. 